\title{
PAINLESS MYOCARDIAL INFARCTION;
}

Its frequency in patients of acute coronary syndrome.

Dr. ljaz-UI-Haque Taseer, Dr. Shahzad Alam Khan, Dr. Muhammad Imran Nazir, Mr. Sohail Safdar

ABSTRACT... Objective: To determine the frequency of painless MI in patients with acute coronary syndrome. Study design: Descriptive cross-sectional study. Setting and duration: This study was conducted at cardiology unit Nishtar Hospital Multan and Chaudhry Pervez Elahi Institute of Cardiology Multan. The study duration was 1 year starting from July 2011 to June 2012. Materials and Methods: This descriptive study included 331 patients of AMI of either sex and age which were admitted at "Cardiology unit Nishtar Hospital Multan and Chaudhry Pervez Elahi Institute of Cardiology Multan" using non-probability convenience sampling technique. Informed verbal consent was taken from each patient for participation. Results: Out of these 331 patients 308 (93.1\%) patients reported chest pain as the presenting complaint. Remaining 23(6.9\%) presented with clinical feature other than chest pain. Of these 23 patients who presented without chest, minimum age was 30 years while maximum was 90 years with mean age $54.82 \pm 12.28$ years. Patients with painless AMI presented with variety of symptoms. Most common symptoms seen in patients of AMI without chest pain were generalized weakness and cold sweats. Out of 23 patients with painless AMI, $15(65.22 \%)$ patients were male and $08(34.8 \%)$ were female. Diabetes mellitus was present as co-morbid condition in 16(69.56\%) while 7(30.44\%) patients were non diabetic. Hypertension was present in 8(34.78\%) patients with painless AMI. Conclusions: Painless AMI or atypical presentation of AMI is seen in substantial proportion of ischemic heart disease patients. Absence of chest pain in AMI patients may misguide the doctors and diverts his attention towards other diagnosis which can lead to considerable delay in the essential therapies required in the management of AMI. It definitely affects morbidity and mortality of emergency department. Health care professionals particularly those working in emergency set up must keep in mind that absence of chest pain in suspected cases of ischemic heart disease does not necessarily rule out AMI. Features of AMI other than chest pain should also be kept in mind while dealing with a suspected case of ischemic heart disease. Further research work on painless AMI and presentation of AMI other than chest pain is needed.

Key words: Chest pain, Acute myocardial infarction, painless MI.

Article Citation

Taseer I, Khan SA, Nazir MI, Safdar S. Painless myocardial infarction; its frequency in patients of acute coronary syndrome. Professional Med J 2013;20(6): 882-886.

\section{INTRODUCTION}

Acute Myocardial infarction (AMI) still remains to be catastrophic cardiac emergency. The clinical diagnosis of AMI requires "typical presentation especially with reference to chest pain in combination with some indirect evidences of myocardial injury established on the basis of biochemical, electrocardiographic and imaging findings". In USA, every year almost 1 million patients suffer from AMI ${ }^{1}$. About 5 million patients report to emergency department every year with history of chest pain ${ }^{2}$ but only 15 to 25 percent of patients with acute chest pain actually have acute coronary syndrome ${ }^{3}$. Frequency of painless myocardial infarction is much higher than that we realize. It is a significant finding because "painless myocardial infarction" most oftenly goes unnoticed by both health care professionals as well as patients thus leading towards inferior care and having worse outcomes. Such patients are at higher risks of developing unpredictable serious ischemic events. Painless MI has been reported in various other studies ${ }^{4}$. Silent presentation of $\mathrm{Ml}$ is known to be an important manifestation of coronary heart disease, however these patients remain neglected due to absence of chest pain ${ }^{5,6}$.

These patients present with the symptoms other than chest pain or discomfort; such angina equivalent symptoms include "dyspnea (most common), nausea, vomiting, diaphoresis, and unexplained fatigue" ${ }^{\text {"7 }}$. In many cases, the sensation is "atypical", with pain experienced in different ways or even being completely absent. Some may report palpitations, anxiety or a sense of impending doom and a feeling of 
being acutely ill. The description of the chest discomfort as a pressure has little value in diagnosis of $\mathrm{AMl}$ as it is non specific for $\mathrm{ACS}^{8}$.

The population of AMI patients who present without chest pain has not been well characterized. Although it is widely known that diabetics, morphine addicts and elderly patients of AMI may not have chest pain at presentation ${ }^{9,10}$.

Complete understanding of atypical presentations may help in the earlier identification and treatment of these patients with AMI. Patients with acute myocardial infarction who are mistakenly discharged on the basis of absence of chest pain from the emergency department have short-term mortality rates of about 25 percent, which is at least twice what would be expected if they were admitted ${ }^{11}$.

It is therefore of utmost importance to emphasize the evaluation of those patients of acute myocardial infarction who do not present with chest pain but present with symptoms other than chest pain. By doing this, we can eliminate the chances of mistaken discharge of patients having painless AMI. Early diagnosis and management of these patients will reduce morbidity and mortality in these patients. So the present study was conducted to find out the frequency of painless AMI in our population and will help to identify those AMI patients who present with atypical features.

\section{MATERIALAND METHODS}

This descriptive study included 331 patients of AMI of either sex and age which were admitted at "Cardiology unit Nishtar Hospital Multan and Chaudhry Pervez Elahi Institute of Cardiology Multan" using nonprobability convenience sampling technique. Informed verbal consent was taken from each patient for participation. The data were recorded on a predesigned questionnaire and were entered and analyzed using SPSS- 16 .

\section{RESULTS}

Three hundred and thirty one patients who presented with acute myocardial infarction (AMI) were recruited in the study. Mean age of the study cases was $54.99 \pm$ 11.25 years (minimum age 20 and maximum 90 years). Two hundred sixty four (79.8\%) were male and $67(20.2 \%)$ were female patients and male to female ratio was 3.9:1. Three hundred and eight (93.1\%) of patients had reported chest pain to be the presenting complaint. Out of these 331 patients, 23(6.9\%) presented with some clinical features other than that of chest pain. Of these 23 patients who presented without chest, minimum age was 30 years while maximum was 90 years with mean age $54.82 \pm 12.28$ years (Table-l). Patients with painless AMI presented with variety of symptoms. Most common symptoms seen in patients of AMI without chest pain were generalized weakness and cold sweats (Table-2). In majority of the patients different combination of symptoms were present rather than a single symptom. Out of 23 patients with painless AMI, $15(65.22 \%)$ patients were male and $08(34.8 \%$ ) were female. Diabetes mellitus was present as co-morbid condition in $16(69.56 \%)$ while $7(30.44 \%)$ patients were non diabetic. Hypertension was present in 8(34.78\%) patients with painless AMI.

\begin{tabular}{|c|c|c|}
\hline Age group (years) & Frequency & \%age \\
\hline $30-40$ & 01 & $4.35 \%$ \\
\hline $41-50$ & 09 & $39.13 \%$ \\
\hline $51-60$ & 10 & $43.47 \%$ \\
\hline 61 and above & 03 & $13.05 \%$ \\
\hline Total & 23 & \\
\hline
\end{tabular}

\section{DISCUSSION}

Though major advances have been made in the management of cardiovascular diseases, yet early identification of patients with painless AMI remains a dilemma. Unfortunately not enough material is 


\begin{tabular}{|l|c|c|c|c|c|}
\hline \multirow{2}{*}{ Presenting complaints } & \multicolumn{2}{|c|}{ Yes } & \multicolumn{2}{c|}{ Notal } \\
\cline { 2 - 5 } & Frequency & \%age & Frequency & \%age & \\
\hline Cold sweats & 18 & $78.26 \%$ & 05 & $21.74 \%$ & 23 \\
\hline Generalized weakness & 18 & $78.26 \%$ & 05 & $21.74 \%$ & 23 \\
\hline Vomiting & 15 & $65.22 \%$ & 08 & $34.78 \%$ & 23 \\
\hline Palpitation & 09 & $39.13 \%$ & 14 & $60.87 \%$ & 23 \\
\hline Syncope & 05 & $21.74 \%$ & 18 & $78.26 \%$ & 23 \\
\hline
\end{tabular}

Table-II. Presentation of AMl patients without chest pain $(n=23)$

available which may help to diagnose those AMI patients who present without chest pain. In our study frequency of painless AMI was $6.9 \%$. Dorsch et $\mathrm{al}^{12}$ identified 3684 consecutive cases with a possible diagnosis of acute myocardial infarction based on coronary care registers, clinical coding, and cardiac enzyme test results. The diagnosis was confirmed in 2096 patients, $20 \%$ of whom had presented without chest pain ${ }^{12}$. Canto $\mathrm{JG}_{\mathrm{G}}$ et $\mathrm{al}^{13}$, reported in this study that $33 \%$ did not have chest pain on presentation to the hospital. This proportion is somewhat higher than has been reported in previous studies ${ }^{14,15,16}$. The reason for low frequency of painless AMI in our setting may be due to lack of health education and awareness. Majority of the people have misconcept that AMI patients always have chest pain so the patients of AMI reported to the hospital without chest pain were less.

In our study we found that majority of the patients i.e. $19(82.6 \%)$ were between the age of 41-60 years and mean age was $54.82 \pm 12.28$ years. Canto $\mathrm{JG}^{13}$ noticed that average age for painless AMI is 74.2 years, it may be because average lifespan in their population is high, hence they have seen more cases in average age group of 74.2 years. Secondly, among south Asian the mean age for first MI is lower than the individuals in other countries ${ }^{17}$. This may be genetic variation.

At any given age, prevalence of AMI is greater in men than in women ${ }^{18}$.
We found that out of 23 patients with painless AMI, $15(65.22 \%)$ patients were male and $08(34.8 \%)$ were females, while out of 308 patients who had chest pain with AMI 264(79.8\%) were male and 67(20.2\%) were females. So, the frequency of painless AMl as compared to the AMI with chest pain was comparatively higher in females (34.8\% vs $20.2 \%$ ). Canto et $\mathrm{al}^{13}$, had observation that frequency of painless AMI in females was $49 \%$ as compared to $38 \%$ frequency in a group of those who presented with chest pain. So the painless AMI was noted more in females as compared to males. The reason may be hormonal variations. In our study there were $16(69.56 \%)$ patients with diabetes, out of them 9(56.25\%) were male and $7(43.75 \%)$ were females. Acharya et $\mathrm{al}^{9}$ have also found that patients with diabetes mellitus may not have chest pain during AMI (possibly secondary to diabetic neuropathy). Canto et $\mathrm{al}^{13}$, found that frequency of diabetes in patients with painless AMI was $32.6 \%$. While in our series it is $69.56 \%$.

\section{CONCLUSIONS}

Painless AMI or atypical presentation of AMI is seen in substantial proportion of ischemic heart disease patients. Absence of chest pain in AMI patients may misguide the doctors and diverts his attention towards other diagnosis which can lead to considerable delay in the essential therapies required in the management of AMI. It definitely affects morbidity and mortality of emergency department. Health care professionals 
particularly those working in emergency set up must keep in mind that absence of chest pain in suspected cases of ischemic heart disease does not necessarily rule out $A M I$. Features of $A M I$ other than chest pain should also be kept in mind while dealing with a suspected case of ischemic heart disease. Further research work on painless AMI and presentation of AMI other than chest pain is needed.

\section{Copyright(C) 17 Aug, 2013.}

\section{REFERENCES}

1. American Heart Association: Heart Diseases and Stroke Statistics-2004 Update. Dallas, American Heart Association, 2003.

2. National Center for Health Statistics, Stussman BJ. National hospital ambulatory medical care survey: 1995: emergency department summary. Advance data from vital and health statistics. No. 285. Hyattsville, Md.: Public Health Service, 1997. (DHHS publication no. (PHS) 97-1250.

3. Pope JH, Aufderheide TP, Ruthazer R, Woolard RH, Feldman JA, Beshansky JR, et al. Missed diagnoses of acute cardiac ischemia in the emergency department. N Engl J Med 2000; 342:1163-1170.

4. Barron HV, Bowlby LJ, Breen T, Rogers WJ, Canto JG, Zhang $Y$, et al. Use of reperfusion therapy for acute myocardial infarction in the United States. Circulation.1998;97:1150-1156.

5. Gregoratos G. Clinical manifestations of acute myocardial infarction in older patients. Am J Geriatr Cardiol 2001;10,345-347.

6. Uretsky, BF, Farquhar, DS, Berezin, AF, Hood WB. Symptomatic myocardial infarction without chest pain: prevalence and clinical course. Am J Cardiol 1977;40,498-50.

7. Abidov A, Rozanski A, Hachamovitch R, Hayes SW, Enein FA, Cohen I, et al. Prognostic significance of dyspnea in patients referred for cardiac stress testing. N Engl J Med. 2005; 353 (18):1889-1898.

8. Woo KM, Schneider Jl (November 2009). "High-risk chief complaints I: chest pain--the big three". Emerg.
Med. Clin. North Am. 27 (4):685-712, x doi:10.1016/j.emc.2009.07.007. PMID 19932401.

9. Acharya DU, Shekhar YC, Aggarwal A, Anand IS. Lack of pain during myocardial infarction in diabetics: is autonomic dysfunction responsible? Am J Cardiol.1991;68:793-796.

10. McGuine DK, Granger CB: Diabetes and ischemic heart disease. Am Heart J.138:366, 1999).

11. Lee TH, Rouan GW, Weisberg MC, Brand DA, Acampora D, Stasiulewicz C, et al. Clinical characteristics and natural history of patients with acute myocardial infarction sent home from the emergency room. Am J Cardiol 1987; 60 (4): 219-224.

12. Dorsch MF, Lawrance RA, Sapsford RJ, Durham N, Oldham J, Greenwood DC, et al. Poor prognosis of patients presenting with symptomatic myocardial infarction but without chest pain. Heart 2001;86:494-8.

13. Canto JG, Shlipak MG, Rogers WJ, Malmgren JA, Frederick PD, Lambrew CT, et al. Prevalence, clinical characteristics, and mortality among patients with myocardial infarction presenting without chest pain. JAMA. 2000;283(24):3223-3229. ,

14. Goldstein RE, Boccuzzi SJ, Cruess D. Prognosis after hospitalization for acute myocardial infarction not accompanied by typical ischemic chest pain. The multicenter diltiazem postinfarction trial research group. Am J Med 1995; 99:123-31.

15. Herlitz J, Karlson BW, Richter A. Prognosis for patients with initially suspected acute myocardial infarction in relation to presence of chest pain. Clin Cardiol 1992;15:570-6.

16. Woong CK, White HD. Recognizing painless heart attacks. Heart 2002; 87 (1): 3-5.

17. Joshi P, Islam P, Pais P, Reddy S, Dorairaj P, Kazmi K, et al. Risk factors for early acute myocardial infarction in south Asians compared with individuals in other countries. JAMA 2007; 297:286-94.

18. Wegner NK, Speroff L, Packard B. Cardiovascular health and disease in women. N Engl J Med 1999; 341:217-25. 


\section{Acknowledgments}

The authors of this article are thankful to Mr. Muhammad Ilyas Qaisar, PMRC Research Centre,
Nishtar Medical College, Multan for his help in data entry.

\section{AUTHOR(S):}

1. DR. IJAZ-UL-HAQUE TASEER

MBBS, MD,

Chief Research Officer,

PMRC Research Centre, Nishtar Medical College, Multan

2. DR. SHAHZAD ALAM KHAN

FCPS,

Senior Registrar

Nishtar Hospital, Multan.

3. DR. MUHAMMAD IMRAN NAZIR

FCPS

Assistant Professor

King Edward Medical University, Lahore
4. Mr. Sohail Safdar

M. Sc

Research Officer

PMRC Research Centre, Nishtar Medical College, Multan

Correspondence Address:

Dr. ljaz-UI-Haque Taseer

MBBS, MD,

Chief Research Officer,

PMRC Research Centre, Nishtar Medical College, Multan. dritaseer@hotmail.com, pmrcnmc@gmail.com

Article received on: $\quad$ 06/05/2013

Medical Journal
to be handled in electronic form throughout the publication process.
Accepts electronic submission of articles via e-mail, attachment in
MS Word format at following address:
info@theprofesional.com
editor@theprofesional.com
publication@theprofesional.com
for more details, visit us ;
www.theprofesional.com

